\title{
The design of the experiments of arsenic removal from aqueous solutions onto Fe-XAD8-DEHPA
}

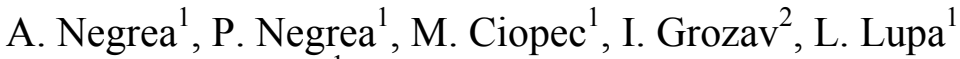 \\ \& C. M. Davidescu ${ }^{1}$ \\ ${ }^{1}$ Faculty of Industrial Chemistry and Environmental Engineering, \\ University "Politehnica" Timisoara, Romania \\ ${ }^{2}$ Faculty of Mechanics, University "Politehnica" Timisoara, Romania
}

\begin{abstract}
One of the main aims for a process is to find the optimum values of the parameters which assure the desired values of the process responses. This activity must be made in the minimum of the time and with the minimum use of consumable resources. The design of the experiments (DoE) assisted by the computer assures that this happens. In this paper, DoE was used to study the adsorption performance of Fe-XAD8-DEHPA in the removal process of As(V) ions from aqueous solutions. It was observed that the Adsorption Capacity and the Efficiency in the removal process of $\mathrm{As}(\mathrm{V})$ from the aqueous solution was significantly influenced by concentration and $\mathrm{pH}$. The mathematical model of the process is very good. It includes the experimental data of over $99 \%$ in the case of adsorption capacity and over $97 \%$ in the case of efficiency. From the contour plots of adsorption capacity and efficiency can be seen that the chemical process is nonlinear. The DOE helped us to find the optimum values of the control factors $(\mathrm{pH}$, contact time and arsenic initial concentrations from solutions) in order to obtain maximum values of Adsorption Capacity and Efficiency. Keywords: arsenic adsorption, Fe-XAD8-DEHPA, design of experiments.
\end{abstract}

\section{Introduction}

In this paper, the design of experiments (DoE) was used to study the adsorption performance of Fe-XAD8-DEHPA in the removal process of As(V) ions from aqueous solutions. 
The presence of dissolved arsenic in groundwater has created significant concern on a global basis. Consumption of arsenic containing water causes serious health-related problems because of its toxicity [1-7]. Thus, choosing a technology for the removal of arsenic from drinking water often represents a challenge. Numerous methods are proposed to reduce arsenic level in natural waters. From all these methods, adsorption proved to be the most effective procedure in arsenic removal, even from very low concentration solutions. From the variety of the adsorbents studied by workers, the use of macro porous organic polymer supports, with a high surface area and good mechanical stability, is found more suitable for the removal of toxic elements from dilute solution, due to their faster kinetics, ease of regeneration and high adsorption capacity [1-10]. In this study the Amberlite XAD8 resin was impregnated, through the most widely used method (dry method), with di(2-ethylhexyl) phosphoric acid (DEHPA) [11-14]. Because the iron compounds in general were found to be very efficient adsorbents for arsenic removal from water due to the high affinity of arsenic towards iron, the XAD8-DEHPA was loaded with Fe(III) ions [2, 3, $6-10,13,14]$.

The use of statistical methods in industry is increasing. The goal of all technological process is to improve the quality and increase the productivity with the minimum of time and costs. The design of experiments has the role to achieve this goal, being centered around factors, responses and runs [15]. In the present paper the optimization of the adsorption process of $\mathrm{As}(\mathrm{V})$ from aqueous solution onto $\mathrm{Fe}(\mathrm{III})$-loaded XAD8 impregnated resin, containing di(2ethylhexyl) phosphoric acid (DEHPA), was studied by using the design of experiments, a statistical method based on the analysis of experimental adsorption data and not on theoretical models.

\section{Experimental}

The studied adsorbent is Amberlite XAD8 resin which was impregnated with di(2-ethylhexyl) phosphoric acid (DEHPA) and then was loaded with $\mathrm{Fe}(\mathrm{III})$ ions. In order to determine the adsorption performance of Fe-XAD8-DEHPA resin, in the removal process of $\mathrm{As}(\mathrm{V})$ from aqueous solution, the influence of different physicochemical parameters $(\mathrm{pH}$, contact time and initial concentration of $\mathrm{As}(\mathrm{V})$ from solution) upon the adsorption capacity and removal efficiency was studied. The physicochemical parameters are called control factors, or variables and the adsorption capacity and removal efficiency are called process responses. The goal of our research was to find which are the optimum values of the control factor in order to obtain higher values of the adsorption capacity and efficiency in the removal process of $\mathrm{As}(\mathrm{V})$ from aqueous solution by adsorption onto Fe-XAD8-DEHPA resin. The advantage of use of the DOE in the adsorption process of $\mathrm{As}(\mathrm{V})$ from aqueous solution onto the studied resin is that the DOE can use simultaneous all the variables, in a wide range of values, in order to predict the responses. With the DOE is possible to find the best combination of the physicochemical parameters in order to obtain the higher values of adsorption capacity and efficiency. 
Because there are only three control factors, Time, Concentration and $\mathrm{pH}$, has been made a nonlinear experiment, using Response Surface Method (RSM) [16]. This RSM is useful for modeling and analyzing the problems in which the response is influenced by several variables and the main target is to optimize the response. In this case the first step is to find a suitable approximation for the functional relationship among the response and the set of the independent variables. Because usually the processes are nonlinear, then a polynomial of second order must be used in so called second-order model $[16,17]$.

The nonlinear experiments are used when we are at a point on the response surface that is remote from the optimum. The objective is to lead rapidly and efficiently along a path of improvement toward the general vicinity of the optimum (Figure 1). A second order experiment type central composite was design using software MINITAB 15. This design is presented in table 1.

Table 1: $\quad$ Central composite design.

\begin{tabular}{|c|c|c|c|c|}
\hline $\begin{array}{c}\text { Time, } \\
\min \end{array}$ & $\begin{array}{c}\text { Concentration, } \\
\mu \mathrm{g} / \mathrm{L}\end{array}$ & $\mathrm{pH}$ & $\begin{array}{c}\text { Adsorption } \\
\text { capacity, } \mu \mathrm{g} / \mathrm{g}\end{array}$ & $\begin{array}{c}\text { Efficiency, } \\
\%\end{array}$ \\
\hline 8 & 10 & 9 & 1.09 & 43.8 \\
\hline 24 & 300 & 4 & 47.06 & 63.5 \\
\hline 16 & 155 & 6.5 & 18.18 & 47.16 \\
\hline 8 & 300 & 9 & 48.79 & 66.03 \\
\hline 24 & 10 & 4 & 0.69 & 28 \\
\hline 8 & 300 & 4 & 44.6 & 60.53 \\
\hline 16 & 155 & 6.5 & 18.18 & 47.16 \\
\hline 24 & 10 & 9 & 0.84 & 33.8 \\
\hline 8 & 10 & 4 & 0.97 & 39.1 \\
\hline 24 & 300 & 9 & 49.31 & 66.47 \\
\hline 16 & 155 & 6.5 & 18.18 & 47.16 \\
\hline 16 & 155 & 6.5 & 18.28 & 47.35 \\
\hline 16 & 155 & 4 & 14.15 & 36.71 \\
\hline 16 & 155 & 6.5 & 18.23 & 47.29 \\
\hline 16 & 300 & 6.5 & 48.17 & 65.9 \\
\hline 16 & 155 & 9 & 14.81 & 38.9 \\
\hline 24 & 155 & 6.5 & 18.86 & 48.9 \\
\hline 16 & 155 & 6.5 & 18.18 & 47.16 \\
\hline 8 & 155 & 6.5 & 17.83 & 46.43 \\
\hline 16 & 10 & 6.5 & 0.86 & 34.5 \\
\hline
\end{tabular}




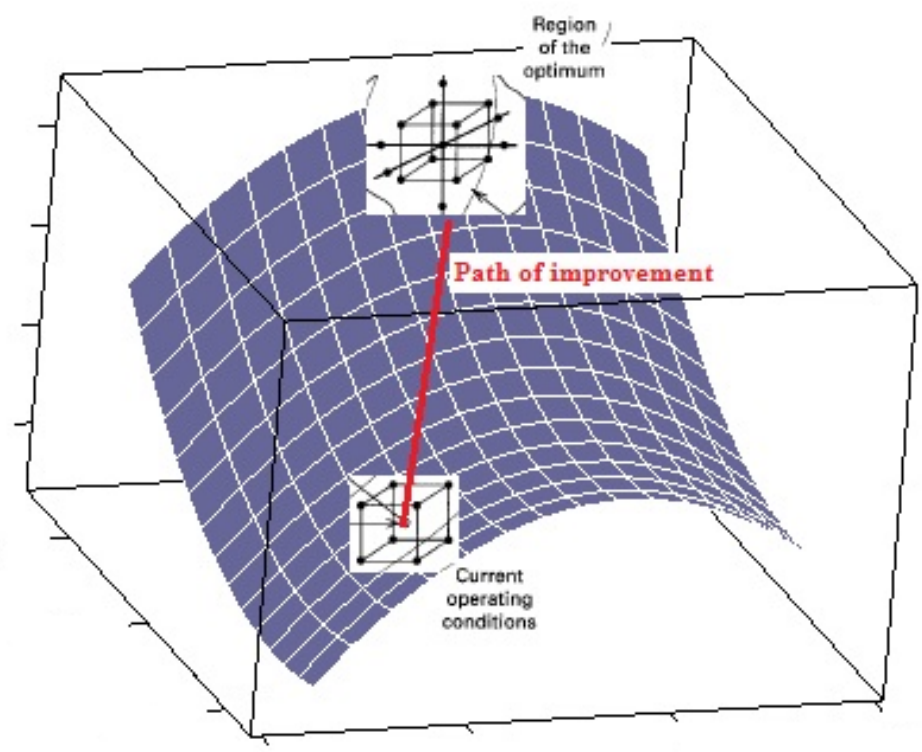

Figure 1: The path of improvement.

\section{Results and discussions}

The analyses of the experiment, using coded units estimated regression coefficients for Adsorption Capacity are presented in table 2 and for Efficiency are presented in table 3 .

Table 2: $\quad$ Estimated regression coefficients for adsorption capacity.

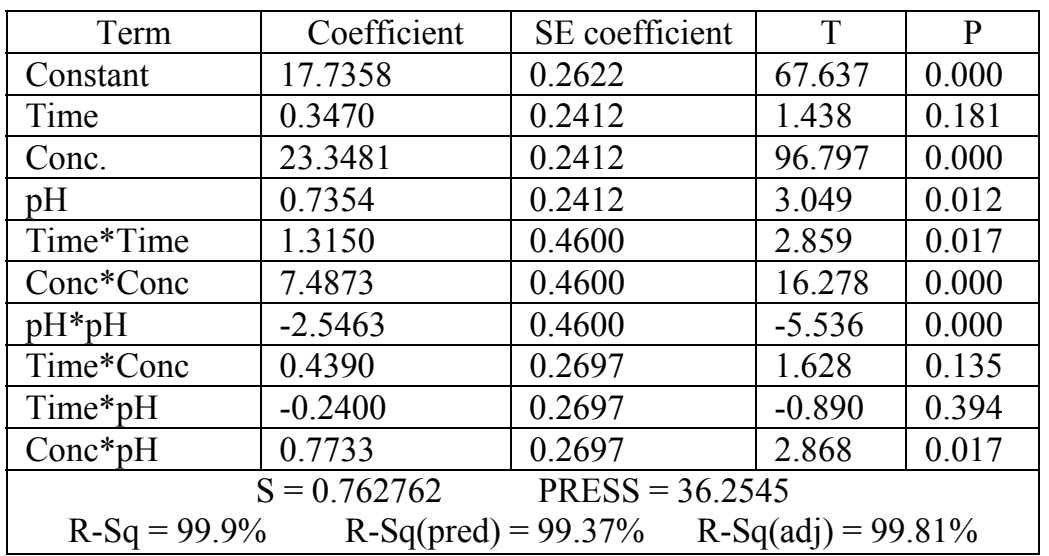


Table 3: $\quad$ Estimated regression coefficients for efficiency.

\begin{tabular}{|l|l|l|l|l|}
\hline \multicolumn{1}{|c|}{ Term } & \multicolumn{1}{c|}{ Coefficient } & \multicolumn{1}{c|}{ SE coefficient } & \multicolumn{1}{c|}{$\mathrm{T}$} & \multicolumn{1}{c|}{$\mathrm{P}$} \\
\hline Constant & 45.9186 & 0.8611 & 53.323 & 0.000 \\
\hline Time & -1.5223 & 0.7921 & -1.922 & 0.084 \\
\hline Conc. & 14.3233 & 0.7921 & 18.082 & 0.000 \\
\hline $\mathrm{pH}$ & 2.1160 & 0.7921 & 2.671 & 0.023 \\
\hline Time*Time & 3.6907 & 1.5105 & 2.443 & 0.035 \\
\hline Conc*Conc & 6.2261 & 1.5105 & 4.122 & 0.002 \\
\hline $\mathrm{pH}$ * pH & -6.1674 & 1.5105 & -4.083 & 0.002 \\
\hline Time*Conc & 3.0625 & 0.8856 & 3.458 & 0.006 \\
\hline Time*pH & -0.1792 & 0.8856 & -0.202 & 0.844 \\
\hline Conc*pH & -0.2542 & 0.8856 & -0.287 & 0.780 \\
\hline \multicolumn{5}{|c|}{ PRESS $=388.230$} \\
\hline
\end{tabular}
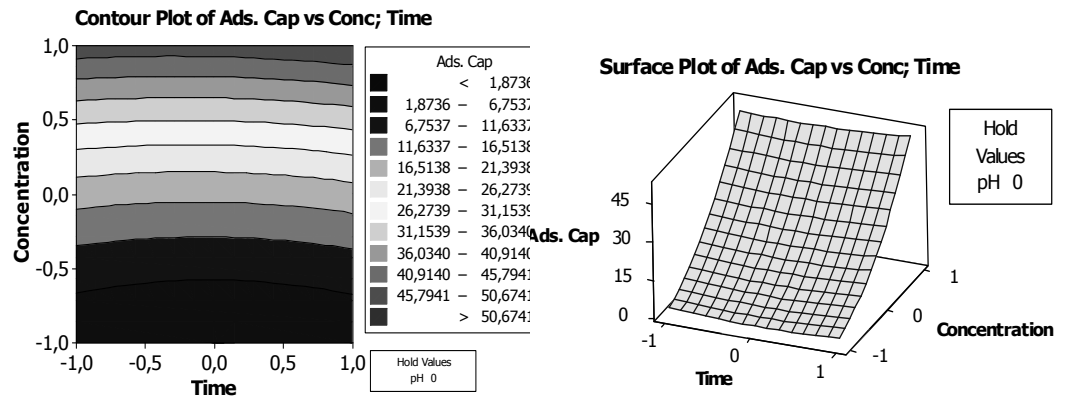

Contour Plot of Ads. Cap vs pH; Time

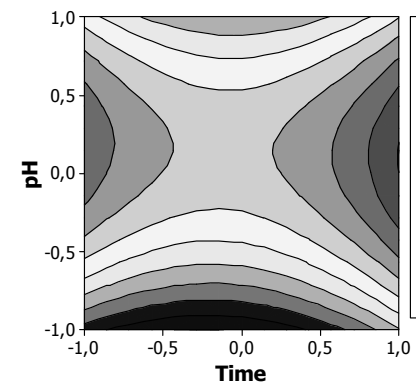

Contour Plot of Ads. Cap vs pH; Conc

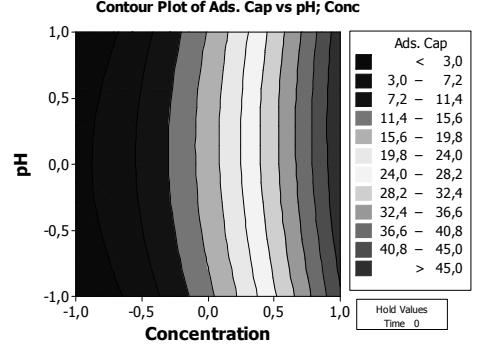

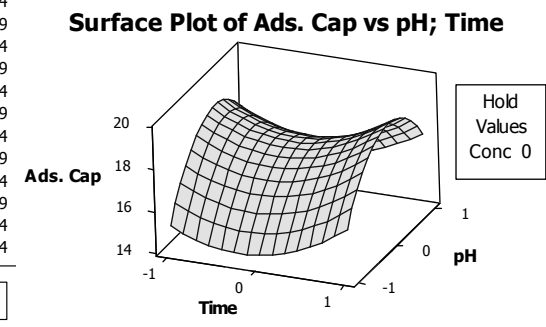

Surface Plot of Ads. Cap vs pH; Conc

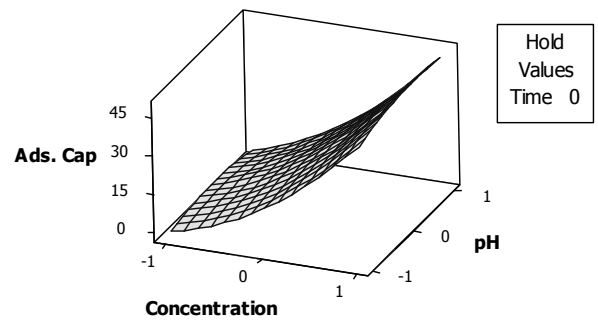

Figure 2: Contour and surface plots for adsorption capacity. 
The Adsorption Capacity is significantly influenced by the Concentration, $\mathrm{pH}$ and by the second order interactions Conc*Conc, $\mathrm{pH}^{*} \mathrm{pH}$, Time*Time, and Conc*pH. The mathematical model in this case is very good, over $99 \%$ of the experimental data are inclusive in this mathematical model.

Efficiency is significantly influenced by Concentration and $\mathrm{pH}$. It is also significantly influenced by the second order interaction $\mathrm{pH}^{*} \mathrm{pH}$, Conc*Conc, Time*Time, and Time*Conc. This mathematical model is also very good, over $97 \%$ of the experimental data are inclusive in this mathematical model.

Adsorption Capacity and Efficiency show that significant weight have had the interaction of the second order. That means we must be very careful when we draw conclusions.

The contour plots and surface plots for Adsorption are presented in figure 2 .

Both contour plot and surface plot show the nonlinear influence of the control factors upon adsorption capacity. The contour plot and surface plot for $\mathrm{pH}$ and Time put in evidence the saddle form of the surface. All other dependences are a surface which assure maximum of adsorption capacity for maximum values for Concentration.

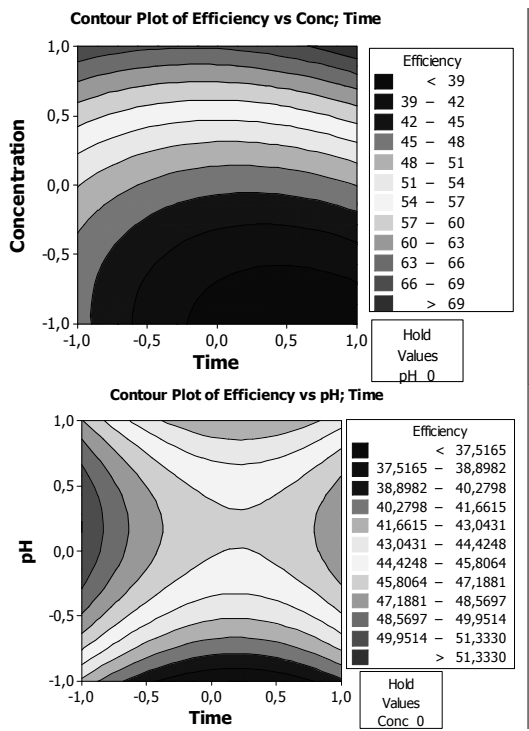

Surface Plot of Efficiency vs Conc; Time
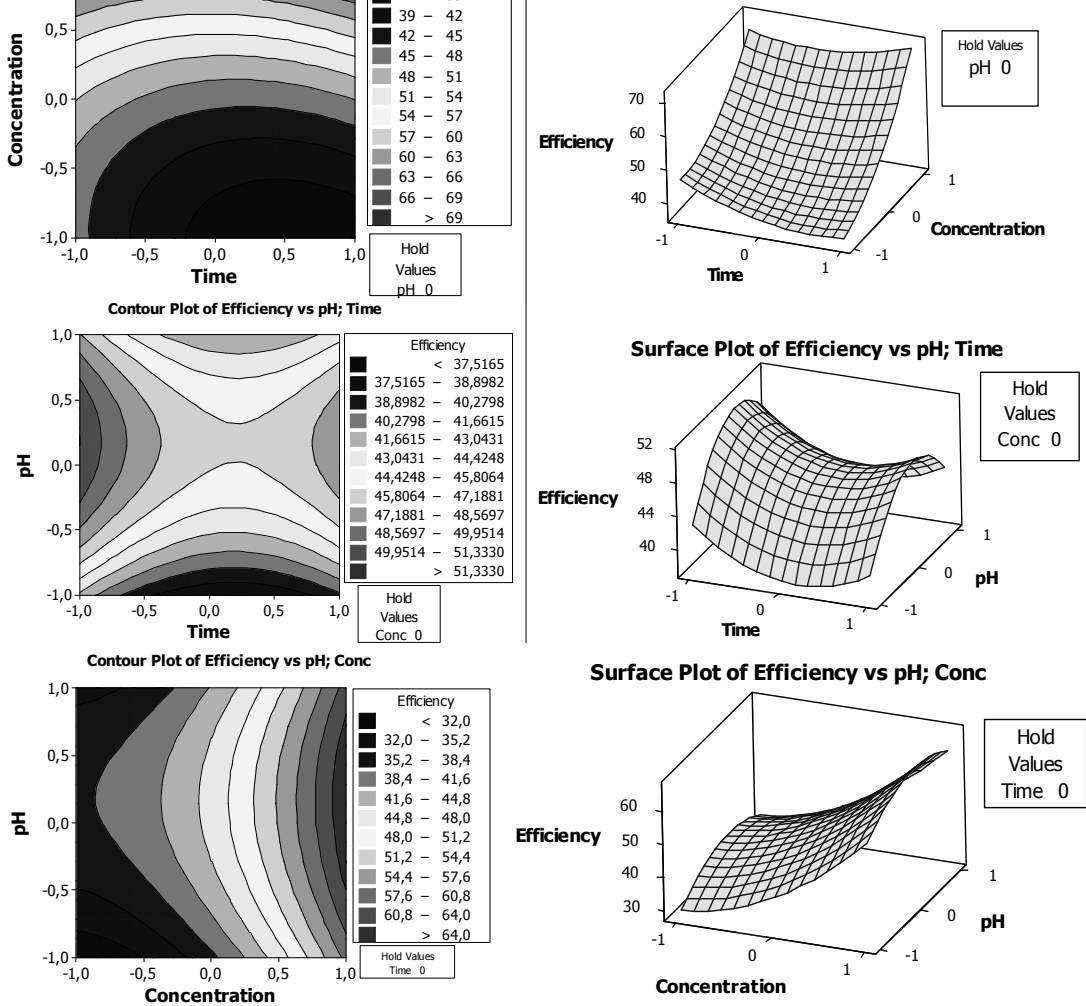

Surface Plot of Efficiency vs pH; Conc

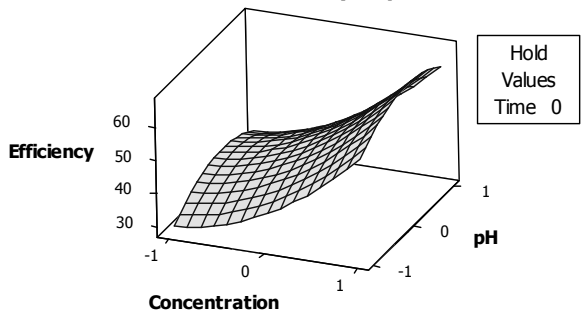

Figure 3: Contour and surface plots for efficiency. 
The contour and surface plots for Efficiency are presented in figure 3. From figure 3 can be seen that the chemical process is nonlinear. The maximum values for Concentration will assure a maximum for efficiency. In the case of Efficiency the surfaces are in the form of a saddle in the case of Time-pH and also a light in the case of $\mathrm{pH}-$ Conc.

For our process it is important to have maximum values for Adsorption Capacity and Efficiency. For this reason in figure 6 the overlaid contour plot of Adsorption Capacity and Efficiency has been shown. The aim was to see the domain of control factor setting for having the maximum values of responses.

Figure 4 shows that for maximum values of the process responses the Concentration must be set at a maximum value, $\mathrm{pH}$ in the middle of the setting domain and Time can be anywhere in the setting domain.
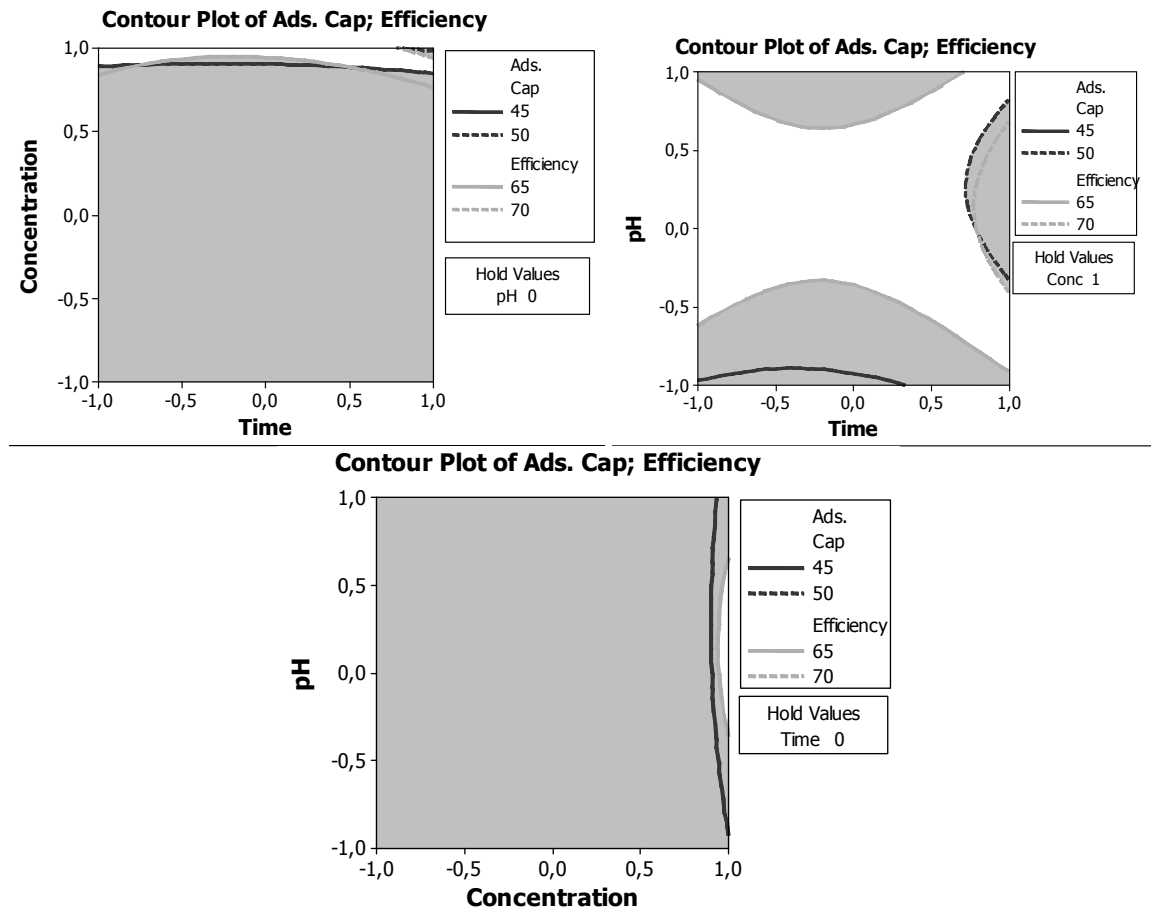

Figure 4: Overlaid contour plot for adsorption capacity and efficiency.

A better optimization can be achieved using the optimizer of the MINITAB. To do this some target values for Adsorption Capacity (Adsorption Capacity $=52$ ) and Efficiency (Efficiency = 75) must be selected. The result of optimization is presented in figure 5 . 


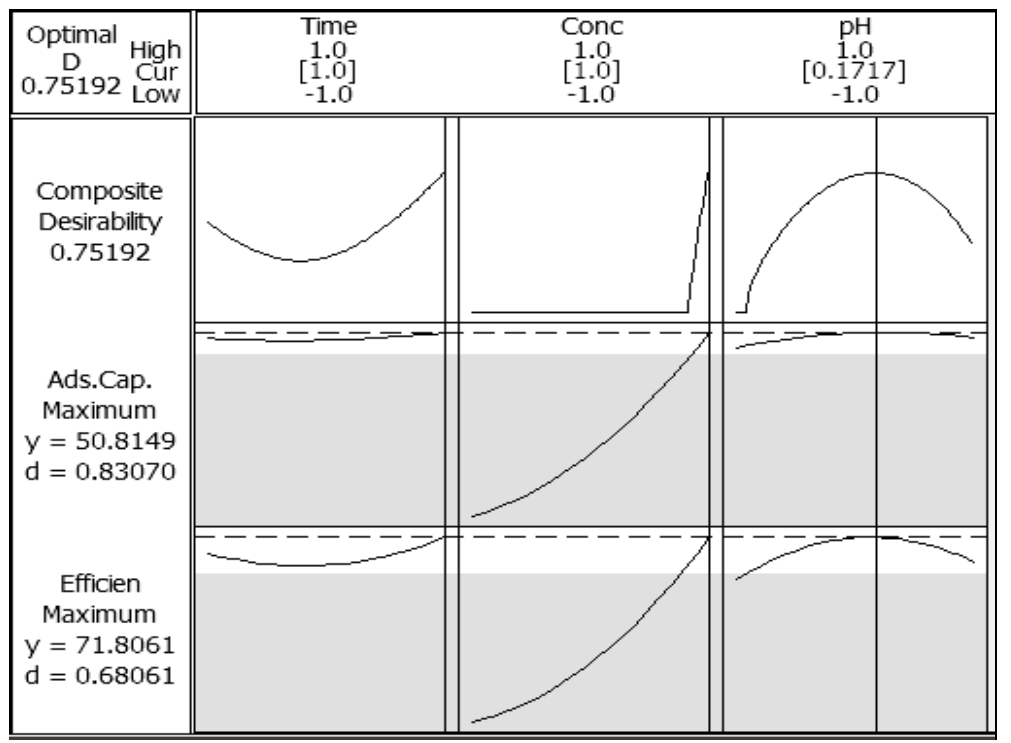

Figure 5: Optimal values for control factors.

The optimal values for control factors can be seen in the top row of figure 5 . These optimal values are presented in table 4.

Table 4: Response optimization.

\begin{tabular}{|c|c|c|c|c|c|c|}
\hline \multicolumn{7}{|l|}{ Parameters } \\
\hline & Goal & Lower & Target & Upper & Weight & Import \\
\hline Ads. Cap. & Maximum & 45 & 52 & 52 & 1 & 1 \\
\hline Efficiency & Maximum & 65 & 75 & 75 & 1 & 1 \\
\hline \multicolumn{7}{|c|}{ Global Solution } \\
\hline & & Time & $=$ & \\
\hline & & Conc. & & \\
\hline & & $\mathrm{pH}$ & \multicolumn{4}{|c|}{$=0.171717$} \\
\hline \multicolumn{7}{|c|}{ Predicted Responses } \\
\hline \multirow{2}{*}{\multicolumn{7}{|c|}{$\begin{array}{ll}\text { Ads. Cap. }=50.8149, & \text { desirability }=0.830700 \\
\text { Efficiency }=71.8061, & \text { desirability }=0.680605\end{array}$}} \\
\hline & & & & & & \\
\hline \multicolumn{7}{|c|}{ Composite desirability $=0.751916$} \\
\hline
\end{tabular}

It can be seen that for maximum values of Adsorption Capacity and Efficiency, Time and Concentration must be set on the maximum values in the setting domain and $\mathrm{pH}$ nearly the middle of the setting domain. 


\section{Conclusions}

One of the main aims for a process is to find the optimum values of the parameters which assure the desired values of the process responses. This activity must be made in the minimum of time and with a minimum of consumable resources. The design of the experiments (DoE) assisted by the computer assures that this happens. In this paper the optimization of the chemical process of $\mathrm{As}(\mathrm{V})$ removal from aqueous solutions by adsorption onto Fe-XAD8DEHPA resin is presented. It was observed that the Adsorption Capacity and the Efficiency in the removal process of $\mathrm{As}(\mathrm{V})$ from aqueous solution was significantly influenced by concentration and $\mathrm{pH}$. The mathematical model of the chemical process is very good, over $99 \%$ in the case of adsorption capacity and over $97 \%$ in the case of efficiency of experimental data are include in model. In these conditions the regression coefficients were estimated. From the contour plots of adsorption capacity and efficiency it can be seen that the chemical process is nonlinear. The DOE helped us to find the optimum values of the control factors $(\mathrm{pH}$, contact time and arsenic initial concentrations from solutions) in order to obtain maximum values of Adsorption Capacity and Efficiency. For maximum values of Adsorption Capacity and Efficiency (called process responses), Time and Concentration must be set on the maximum values in the setting domain and $\mathrm{pH}$ nearly the middle of the setting domain.

\section{Acknowledgements}

This work was partially supported by the strategic grant POSDRU/89/ 1.5/S/57649, Project ID 57649 (PERFORM-ERA), co-financed by the European Social Fund - Investing in People, within the Sectoral Operational Programme Human Resources Development 2007-2013.

\section{References}

[1] Ramesh, A.; Hasegawa, H.; Maki, T.; Ueda, K. Adsorption of inorganic and organic arsenic from aqueous solutions by polimeric $\mathrm{Al} / \mathrm{Fe}$ modified montmorillonite, Sep. Purif. Technol. 2007, 56, 90-100.

[2] Guo, H.; Stuben, D.; Berner, Z. Arsenic removal from water using natural iron mineral-quartz sand columns, Sci. Total Environ. 2007, 377, 142-151.

[3] Kundu, S.; Gupta, A. K. Adsorptive removal of As(III) from aqueous solution using iron oxide coated cement (IOCC): Evaluation of kinetic, equilibrium and thermodynamic models. Sep. Purif. Technol. 2006, 51, 165-172.

[4] Borah, D.; Satokawa, S.; Kato, S.; Kojima, T. Surface-modified carbon black for As(V) removal. J. Colloid Interface Sci. 2008, 319, 53-62.

[5] Borah, D.; Satokawa, S.; Kato, S.; Kojima, T. Sorption of As(V) from aqueous solution using acid modified carbon black. J. Hazard. Mater. 2009, $162,1269-1277$. 
[6] Negrea, A.; Lupa, L.; Ciopec, M.; Lazau, R.; Muntean, C.; Negrea, P. Adsorption of As(III) ions onto iron-containing waste sludge. Adsorpt. Sci. Technol. 2010, 28, 467-484.

[7] Goswami, R.; Deb, P.; Thakur, R.; Sarma, K. P.; Bsumalick, A. Removal of As(III) from aqueous solution using functionalized ultrafine iron oxide nanoparticles. Sep. Sci. Technol. 2011, 46, 1017-1022.

[8] Banerjee, K.; Amy, G. L.; Prevost, M.; Nour, S.; Jekel, M.; Gallagher, P. M.; Blumenschein, C. D. Kinetic and thermodynamic aspects of adsorption of arsenic onto granular ferric hydroxide (GFH). Water Res. 2008, 42, 3371-3378.

[9] Gupta, K.; Ghosh, U. C. Arsenic removal using hydrous nanostructure iron(III)-titanium(IV) binary mixed oxide from aqueous solution. J. Hazard. Mater. 2009, 161, 884-892.

[10] Hlavay, J.; Polyak, K. Determination of surface properties of iron hydroxide coated alumina adsorbent prepared from drinking water. J. Colloid Interface Sci. 2005, 284, 71-77.

[11] Saha, B.; Gill, R.J.; Bailey, D.G.; Kabay, N.; Arda, M. Sorption of Cr(VI) from aqueous solution by AMberlite XAD-7 resin impregnated with ALiquat 336, React. Funct. Polym. 2004, 60, 223-244.

[12] Belkhouche, N. E.; Didi, M. A. Extraction of Bi(III) from nitrate medium by D2EHPA impregnated onto Amberlite XAD-1180. Hydrometallurgy 2010, 103, 60-67.

[13] Negrea, A.; Ciopec, M.; Lupa, L.; Davidescu, C.M.; Popa, A.; Ilia, G.; Negrea, P. Removal of $\mathrm{As}^{\mathrm{V}}$ by $\mathrm{Fe}^{\mathrm{III}}$ loaded XAD7 impregnated resin containing di(2-ethylhexyl) phosphoric acid (DEHPA): Equilibrium, Kinetic and Thermodynamic modelling studies, J. Chem. Eng. Data 2011, 56, 3830-3838.

[14] Ciopec, M.; Negrea, A.; Davidescu, C.M.; Negrea, P.; Muntean, C.; Popa, A. Use of Di-(2-Ethylhexyl)- Phosphoric Acid (DEHPA) Impregnated XAD-8 Copolymer Resin for the Separation of Metal Ions from Water, Chem. Bull. "Politehnica" Univ. Timisoara 2010, 55(69) 2, 127-131.

[15] JMP Designed of Experiments, SAS Institute Inc., Cary, NC, USA, 2005.

[16] Miron, M., Grozav, I., Todea, C., Notiuni Fundamentale de Metodologia Cercetarii Stiintifice Medicale, Ed. Marineasa, Timisoara, 2004, ISBN 973631-189-9.

[17] Montgomery, D.C., Design and Analysis of Experiments, 5-th edition, 2001 by John Wiley \& Sons, Inc., ISBN 0-471-31649-0. 